International Conference on SOCIAL SCIENCE, HUMANITIES \& EDUGATION

21-23 December, 2018 in Berlin - Germany

\title{
Comprehensible Input and Differentiated ESL Instruction
}

\author{
Dr. Lee Gunderson \\ Dr. Reginald Arthur D'Silva \\ University of British Columbia \\ Vancouver, British Columbia, Canada
}

Keywords: Comprehensible Input

ESL

Differentiated Instruction

Student Diversity

\section{Introduction}

One consequence of migration and transnational institutional enrollment is that classrooms and schools have become significantly more diverse culturally, socioeconomically, educationally, and linguistically. Classrooms in jurisdictions where the medium of instruction is English require differentiated instruction to account for students' diversity of knowledge and abilities. A teacher's instructional focus must be the provision of comprehensible input. The difficulty is that comprehensibility is related to a myriad of variables that are unique to an individual rather than to a group; comprehensible input is relative to differences in knowledge of semantics, syntax, pragmatics, orthography, individual development, motivation, educational background, and culture. Differentiated instruction, designed to scaffold the learning of individual students, is complex related to ESL students. This session describes the variables that predict comprehensibility for individual students. These variables are used to produce instructional matrices that outline differentiated ESL instruction. These matrices will be shown, described, and discussed. Their use in $\mathrm{K}-16$ classrooms will be reviewed. 